\title{
Effect of Particulate Matter Exposure on Respiratory Health of e-Waste Workers at Agbogbloshie, Accra, Ghana
}

\author{
Afua Asabea Amoabeng $\mathrm{Nti}^{1, *}$, John Arko-Mensah ${ }^{1}$, Paul K. Botwe ${ }^{1}{ }^{(\mathbb{D}}$, Duah Dwomoh ${ }^{2}{ }^{(\mathbb{D}}$, \\ Lawrencia Kwarteng ${ }^{1}$, Sylvia Akpene Takyi ${ }^{1}$, Augustine Appah Acquah ${ }^{1}{ }^{\circledR}$, Prudence Tettey ${ }^{1}$, \\ Niladri Basu ${ }^{3}$, Stuart Batterman ${ }^{4}$, Thomas G. Robins ${ }^{4}$ and Julius N. Fobil ${ }^{1}$ \\ 1 Department of Biological, Environmental \& Occupational Health Sciences, School of Public Health, \\ University of Ghana, Accra P.O. Box LG13, Ghana; jarko-mensah@ug.edu.gh (J.A.-M.); \\ pkbotwe@ug.edu.gh (P.K.B.); lawkwarps@yahoo.com (L.K.); phykles@gmail.com (S.A.T.); \\ nana.austine@gmail.com (A.A.A.); ptettey@ug.edu.gh (P.T.); jfobil@ug.edu.gh (J.N.F.) \\ 2 Department of Biostatistics, School of Public Health, University of Ghana, Accra P.O. Box LG13, Ghana; \\ duahdwomoh@gmail.com \\ 3 Faculty of Agricultural and Environmental Sciences, McGill University, Montréal, QC H9X 3V9, Canada; \\ niladri.basu@mcgill.ca \\ 4 Department of Environmental Health Sciences, University of Michigan, 1415 Washington Heights, \\ Ann Arbor, MI 48109-2029, USA; stuartb@umich.edu (S.B.); trobins@umich.edu (T.G.R.) \\ * Correspondence: aaamoabeng_nti001@st.ug.edu.gh; Tel.: +233-20-852-1653
}

Received: 23 March 2020; Accepted: 22 April 2020; Published: 27 April 2020

Abstract: Background: Direct and continuous exposure to particulate matter (PM), especially in occupational settings is known to impact negatively on respiratory health and lung function. Objective: To determine the association between concentrations of PM $(2.5,2.5-10$ and $10 \mu \mathrm{m})$ in breathing zone and lung function of informal e-waste workers at Agbogbloshie. Methods: To evaluate lung function responses to PM $(2.5,2.5-10$ and $10 \mu \mathrm{m})$, we conducted a longitudinal cohort study with three repeated measures among 207 participants comprising 142 healthy e-waste workers from Agbogbloshie scrapyard and 65 control participants from Madina-Zongo in Accra, Ghana from 2017-2018. Lung function parameters (FVC, FEV1, FEV1/FVC, PEF, and FEF 25-75) and $\mathrm{PM}(2.5,2.5-10$ and $10 \mu \mathrm{m})$ concentrations were measured, corresponding to prevailing seasonal variations. Socio-demographic data, respiratory exposures and lifestyle habits were determined using questionnaires. Random effects models were then used to examine the effects of PM (2.5, 2.5-10 and $10 \mu \mathrm{m})$ on lung function. Results: The median concentrations of PM $(2.5,2.5-10$ and $10 \mu \mathrm{m})$ were all consistently above the $\mathrm{WHO}$ ambient air standards across the study waves. Small effect estimates per IQR of PM $(2.5,2.5-10$ and $10 \mu \mathrm{m})$ on lung function parameters were observed even after adjustment for potential confounders. However, a $10 \mu \mathrm{g}$ increase in PM $(2.5,2.5-10$ and $10 \mu \mathrm{m})$ was associated with decreases in PEF and FEF $25-75$ by $13.3 \% \%$ [ $\beta=-3.133 ; 95 \%$ CI: $-0.243,-0.022$ ) and $26.6 \%$ $[\beta=-0.266 ; 95 \%$ CI: $-0.437,0.094]$. E-waste burning and a history of asthma significantly predicted a decrease in PEF by $14.2 \%$ [ $\beta=-0.142 ; 95 \%$ CI: $-0.278,-0.008$ ) and FEV1 by $35.8 \%$ [ $\beta=-0.358 ; 95 \%$ CI: $-0.590,0.125]$ among e-waste burners. Conclusions: Direct exposure of e-waste workers to PM predisposes to decline in lung function and risk for small airway diseases such as asthma and COPD.

Keywords: PM exposure; breathing zone; informal e-waste workers; Agbogbloshie; lung function; longitudinal study 


\section{Introduction}

Occupational exposure to particulate matter (PM) has been identified as a major contributing factor of respiratory diseases including reduced lung function. However, very few studies have examined the effects of exposure to PM on respiratory outcomes among informal electronic waste (e-waste) workers with none being conducted among e-waste workers in Ghana. There is the need to provide data to add to intellectual knowledge, inform public health policy and worker health education programming especially in Ghana.

Exposure to airborne particulate matter (PM) present in the work environment could precipitate a myriad of health conditions [1,2], including lung function changes, morbidity and mortality due to respiratory and cardiovascular diseases $[3,4]$. The association between exposure to ambient PM and reduced lung function parameters have been reported in many studies [5-10] and the degree and nature of effect is dependent on PM type, size, ambient concentration, duration of exposure and total lung ventilation period of exposed individuals $[3,11]$. Inhaled particles that can reach the lower airways are categorized into three fractions depending on the size; PM10 (diameter $\leq 10 \mu \mathrm{m}$ ), fine or PM2.5 (diameter $\leq 2.5 \mu \mathrm{m}$ ) and ultrafine, UFP or PM0.1 (diameter $\leq 1 \mu \mathrm{m}$ ). Due to their ubiquitous nature, fine and UFP particles easily penetrate deep into the lungs unfiltered, predisposing to various acute and chronic respiratory health effects. Inhalation of PM into the respiratory tract often induces oxidative stress and generation of reactive oxygen species production, resultant hypersensitivity and inflammation of respiratory lining of which may impact optimal lung function. Prolonged chronic exposure may cause lung tissue remodeling, scarring with fibrosis leading to chronic lung conditions such as asthma, bronchitis, chronic obstructive pulmonary disease (COPD), and even lung cancer $[4,12]$.

One of the conundrums the world face is proper disposal and management of e-waste, due to the several toxic substances they contain. For example, informal electronic waste (e-waste) recycling activities such as manual dismantling and open air burning of cables release several toxic substances including polyromantic hydrocarbons, heavy metals and organic-bound PM into ambient environment [13]. Several studies conducted at the Agbogbloshie informal e-waste site have reported high concentrations of harmful compounds present in ambient air, soil sediments, water bodies and biological fluids (blood and urine) of e-waste workers [13-15]. For instance, (Caravanos, Clark, Fuller, \& Lambertson, 2011) [16] measured high level of lead $\left(0.98 \mathrm{mg} / \mathrm{m}^{3}\right)$ in the breathing zone of one e-waste worker, which was twenty times the American Conference of governmental industrial hygienists' value (ACGIH) permissible threshold limit value (TLV) of $0.05 \mathrm{mg} / \mathrm{m}^{3}$. Iron concentrations in the worker's breathing zone ranged from $1.7-5.6 \mathrm{mg} / \mathrm{m}^{3}$, other heavy metals such as copper and aluminum were also above the accepted ACGIH TLV limits of 5.0 and $1.0 \mathrm{mg} / \mathrm{m}^{3}$ respectively.

The association between exposure to personal ambient PM and reduced lung function parameters has been reported in many occupational and epidemiological studies. These studies have shown a positive correlation between PM exposure and adverse respiratory health conditions [6,17-19]. For instance, both population-based and occupational studies have shown that short and long term exposure to PM, particularly, PM2.5 may predispose to bronchial asthma, chronic obstructive pulmonary disease, and increased respiratory symptoms or worsened pre-existing conditions in susceptible individuals [20]. However, few respiratory health effects studies have been conducted among informal e-waste workers. For instance, a survey among e-waste workers in India found $76 \%$ of the studied population reported respiratory illnesses such as dyspnea, coughs, asthma, and bronchitis [21]. The respiratory health effects of recurrent exposure to PM among informal e-waste recyclers have not been adequately studied. The aim of this study was to assess the effects of exposure to PM $(2.5,2.5-10$ and $10 \mu \mathrm{m})$ in the breathing zone on lung function of healthy informal e-waste workers over time and further investigate if there are seasonal variations of PM lung function outcome parameters within e-waste worker group categories and across study sites.

The manuscript comprise six thematic areas; a brief abstract that summarizes the study, an introduction including the problem statement and objectives. The materials and methods section outlines the study area, the study participants and the methods used in the study. The results are 
presented using graphs and tables for further illustration followed by a comprehensive discussion of results including the strengths and limitations of the study. The manuscript conclusion summarizes the observations made, study limitations and future outlook.

\section{Materials and Methods}

\subsection{Study Area}

The Agbogbloshie informal e-waste recycling site (Figure 1) in Accra, is located in the central business district, bustling with several commercial and industrial activities, and a densely populated settlement [22]. The site is rated by Pure Earth among the top ten most contaminated areas on earth $[23,24]$. E-waste recycling and recovery of valuable parts include activities such as collecting, sorting, dismantling and open air burning of electrical cables to recover copper, each activity presenting unique occupational and environmental health risks. Of major public health concern is the open air burning of sheathed cables with fuel sources such as old discarded car tyres, and foams recovered from old refrigerators etc. [13] which results in the release of mixtures of several harmful substances, including, PM of varying sizes, polyaromantic hydrocarbons, and heavy transitional metals. The airborne particulates released in the burning process get suspended in immediate ambient environment and disperses into surrounding communities. Direct exposure of e-waste recyclers to these toxic chemicals including smoke could greatly increase workers' risk for adverse respiratory impairment such as lung function changes, asthma, COPD (chronic obstructive pulmonary disease) and lung cancer.

Sixty-four ( $n=64$ ) male residents from Madina Zongo, a suburb of Accra in the La Nkwantanang sub-metropolitan district located more than $10 \mathrm{~km}$ from the Agbogbloshie e-waste site were selected as the control population. Madina Zongo was selected as a control population because of similarities in ethnicity and religion, as similar to e-waste workers at Agbogbloshie, majority are of the Dagomba tribe who migrated from northern Ghana, as well as being Muslims [25].

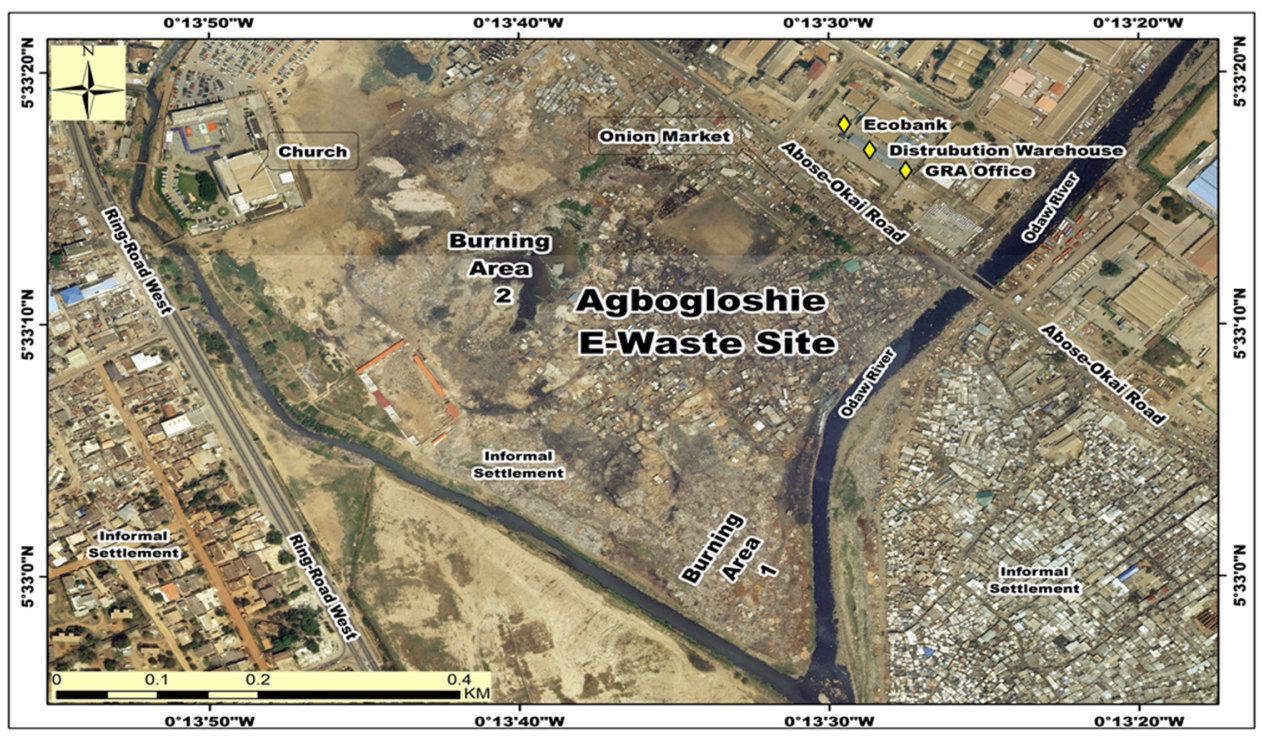

(a)

Figure 1. Cont. 


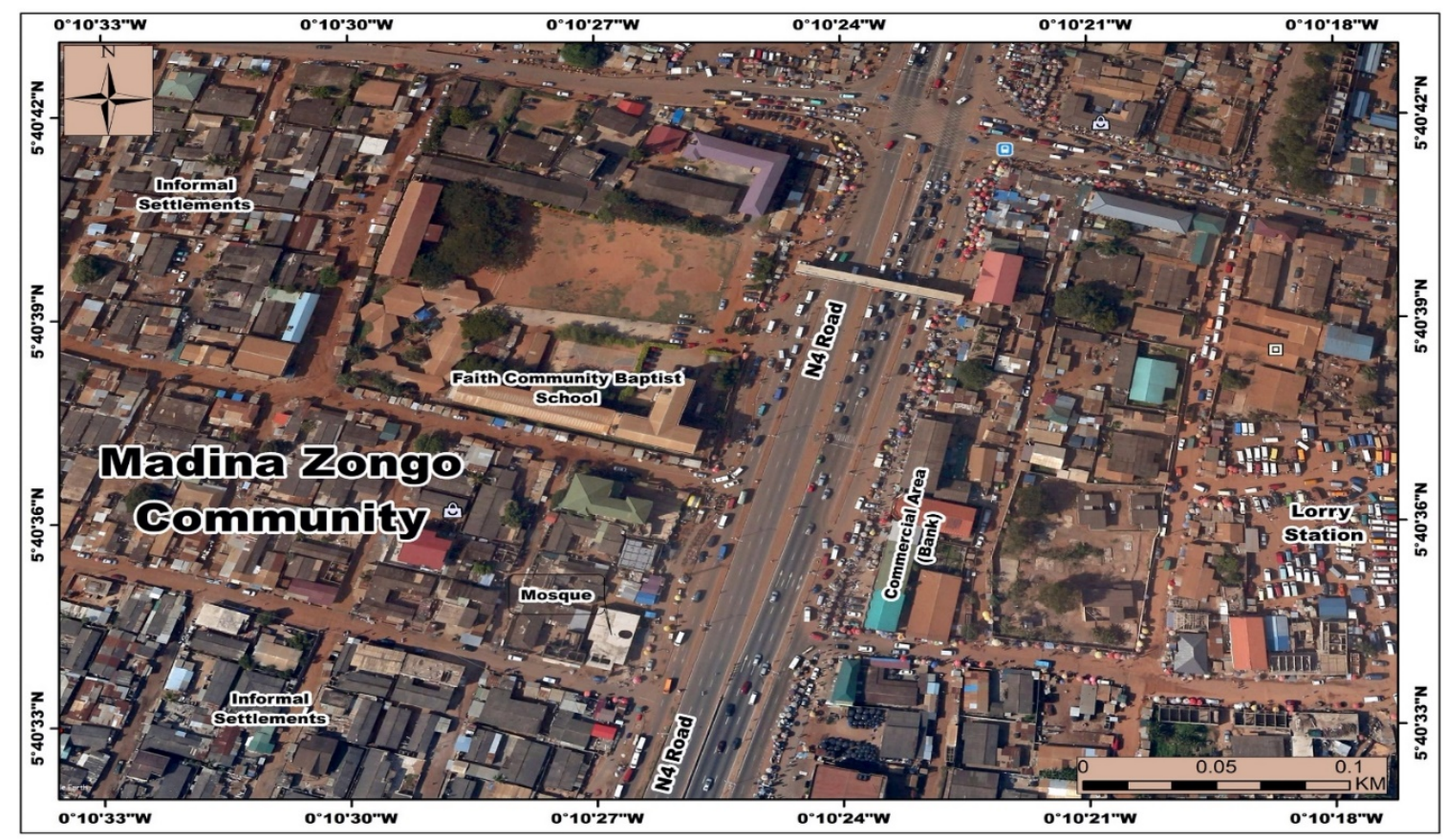

(b)

Figure 1. Google earth map views of study sites, Agbogbloshie and Madina-Zongo, Accra-Ghana. (a) e-waste recycling (exposed site); (b) Madina- Zongo (Control site).

\subsection{Study Design}

We conducted a longitudinal cohort study comprising four rounds of repeated exposure and health outcome measurements among e-waste workers at Agbogbloshie and Madina Zongo from March 2017 to November 2018. After series of community entry procedures to introduce the study and obtain consent from leaders, study staff contacted the workers with the help of recruiters, read out and explained the participant information pamphlets and procedures. Workers who agreed to participate were recruited after they provided written consent by signature or thumbprint. This continued until a total of one hundred (100) male e- waste workers and fifty-one (51) male controls from Madina-Zongo were recruited. Originally, recruitment was planned at round 1 only, however, due to the high participant attrition of $>30 \%$ at round 2, new participants were enrolled (42 and 14 for e-waste workers and controls respectively), to replace those that were lost to follow-up. Subsequently, there were three follow-up data measurements after round 1. Participants were located via mobile phone calls and the help of some identified e-waste workers and individuals in the two communities.

$\mathrm{PM}$ exposure concentration in participants breathing zone and lung function parameter measurements were collected from all participants at each round. Spirometry was performed by qualified medical personnel to measure the lung function of participants, and height and weight were also measured for body mass index estimation. A comprehensive respiratory health questionnaire was used to collect demographic information (age, gender, religion, ethnicity, and education, measures of socioeconomic position, location of birth and childhood and location of all residences), previous work and home inhalational exposures, and personal and family medical history through personal interviews. Data collection periods were aligned to the dry, rainy and harmattan (dry and dust-laden winds blowing from the Sahara desert into the Gulf of Guinea) [26] seasons to assess the effect of seasonality on PM levels and relationship with lung function. At the end of round 4, of the 207 participants recruited, 61 completed all four waves, 82 completed three waves, 25 completed two and 39 completed one wave. Informed consent was obtained, and questionnaires were administered by trained, interpreters in the participants' preferred language of either Dagbani, Hausa, Twi, or English. 
The participants were compensated for their time and loss of daily wages (usually two working days). Each participant received 30 Ghana Cedis (approximately US\$7), a branded T-shirt, and a snack meal. We obtained ethical approval (CHS-Et/M.4-P 3.9/2015-2016) from the Universities of Ghana and Michigan Institutional Review Boards (IRBs).

\subsection{Particulate Matter Exposure Assessment}

Comprehensive description of PM determination can be found in [27]. Briefly, PM in the breathing zone of participants was measured using a MetOne Aerocet 831 particle mass profiler (MetOne Instruments Incorporated, Grants Pass, OR, USA) which simultaneously measured PM2.5 and PM10 levels per minute at a flow rate of $2.8 \mathrm{~L} / \mathrm{min}$. This battery-operated sampler was incorporated into a backpack worn by participants whiles preforming their routine work tasks. Sampling was done for a 4-h period of the work shift. However, during the harmattan season, PM collection was done for $2 \mathrm{~h}$ as the Aerocet pump got overloaded quickly. Readings were recorded at beginning of each deployment and at retrieval respectively. The coarse fraction component was derived by estimating the difference in the concentrations of PM2.5 and PM10.

\subsubsection{Lung Function Measurement}

Each participant performed lung function tests with the use of portable Easyone spirometer (ndd Medical Technologies, Andover, MA). Lung function test was performed by a qualified technician and physician according to the American Thoracic Society (ATS) guidelines [28]. Forced vital capacity (FVC), Forced expiratory volume in one second (FEV1), ratio of Forced expiratory volume in one second and Forced vital capacity (FEV1/FVC), peaked expiratory flow (PEF), and forced expiratory flow 25-75 (FEF25-75) and were measured in the standing position. All lung function data were expressed as predicted z-scores of the normal values according to the NHANES III equation [29]. A minimum of three acceptable FVC maneuvres were performed up to a maximum of six when reproducibility criteria were not met. An end of the test criterion of at least 2 seconds of no change in volume with an exhalation time of at least 6 seconds was used. The largest FVC and FEV1 obtained from any acceptable curves were used for recording purposes. A reproducibility criteria was peaked at less than $5 \%$ variation or $0.1 \mathrm{~L}$ difference of the largest FVC and FEV1. Ethnically appropriate reference values were used for the interpretation of the results (Hankinson, Odencrantz, \& Fedan, 1999) [30]. An abnormal test was defined as less than $80 \%$ or greater than $120 \%$ of predicted (percent predicted) for FVC and FEV1 and $<70 \%$ for FEV1/FVC. The height and weight of the participants were also measured in the upright position without shoes and heavy clothing.

\subsubsection{Covariates}

At enrollment, data on demographics (age, sex, religion, ethnicity, education, occupation, socioeconomic and marital status), detailed current and previous job history and exposures, home exposures including indoor cooking and biomass fuel use, pre-existing medical conditions, and lifestyle habits such as cigarette smoking and alcohol use were collected using a comprehensive questionnaire. Data on cigarette smoking included age at smoking initiation, duration of smoking, sticks smoked per day, current or ex-smoker defined as smoking cessation greater than a month's duration. Smokers were classified as current, ex-, or never-smokers. The questionnaire was administered by trained interviewers in either Dagbani, Twi or English languages according to the participant's preference. Limited interview guides were administered in subsequent follow-up data collection that explored possible changes in home and work exposures, and other respiratory conditions.

\subsection{Statistical Procedures}

Descriptive data were expressed as means and standard deviation, frequency, and percentages where appropriate. A bivariate analysis was performed to compare characteristics of study participants by location using student t-test statistics, and Spearman's rank correlation coefficient and Chi-square 
test of independence to test association between e-waste workers and controls. All the lung function indices were log-transformed to approximate normality. The effects of PM $(2.5,2.5-10$ and $10 \mu \mathrm{m})$ exposures on lung function parameters, (FVC, FEV1, FEV1/FVC ratio PEF, and FEF25-75) parameters were investigated by fitting a random-effects model with random slope effects terms. We used the model to examine the effect of PM $(2.5,2.5-10$ and $10 \mu \mathrm{m})$ on lung function parameters, while controlling for age, education, job category, height, cigarette smoking status, location and seasonal variation. The regression coefficients and confidence intervals were documented. The lung function parameters were presented as Z-score in lung function per $10 \mu \mathrm{g} / \mathrm{m}^{3}$ concentration change in the fine and coarse PM in the participants breathing zones.

For the direct effect of job category on the respiratory outcomes, a power of $90 \%$ was used. This power was computed, using [31]'s formulas for longitudinal studies, at a significance level of 0.05, an exchangeable covariance structure, taking most set parameters (estimated FEV1\% for controls of 90 and SD at 12.5) as those observed in previous similar studies in northern part of Ghana from where participants migrated to Accra.

\section{Results}

\subsection{Socio-Demographic Characteristics of Study Participants}

Generally, e-waste workers were younger $(26.45 \pm 6.74)$ compared to the controls $(30.97 \pm 9.92)$ [Table 1]. More than half, (51.94\%) of study participants were within the 21-30 year age category. 77 $(56 \%)$ of e-waste workers had no formal or primary education compared to the control population with 61\% (46) of respondents having attained a high school education. Mean age, daily income, and educational level were significantly lower among the e-waste workers than the control population. The study found no significant differences in BMI due to exposure to particulate matter and lung function among e-waste workers and non-e-waste workers $(p=0.100)$.

Table 1. Sociodemographic characteristics of study participants. Bold $p$-values represent significant values $(p \leq 0.05)$.

\begin{tabular}{|c|c|c|c|c|}
\hline Variable & $\begin{array}{c}\text { Total } \\
(\mathrm{N}=207)\end{array}$ & $\begin{array}{c}\text { E-Waste Workers } \\
\qquad(\mathrm{N}=142)\end{array}$ & $\begin{array}{c}\text { Non E-Waste } \\
\text { Workers }(\mathrm{N}=65)\end{array}$ & $p$-Value \\
\hline & n (\%) & n (\%) & n (\%) & \\
\hline BMI $\left(\mathrm{kg} / \mathrm{m}^{2}\right):$ mean $\pm \mathrm{SD}$ & $23.37 \pm 3.19$ & $23.19 \pm 3.05$ & $23.75 \pm 3.44$ & 0.100 \\
\hline SPO2 (mean \pm SD) & $96.56 \pm 3.23$ & $96.34 \pm 3.64$ & $97.06 \pm 1.94$ & 0.019 \\
\hline Age in years: mean $\pm S D$ & $27.87 \pm 8.14$ & $26.45 \pm 6.74$ & $30.97 \pm 9.92$ & $<0.001$ \\
\hline Age category & & & & 0.05 \\
\hline$\leq 20$ years & $39(18.93)$ & $30(21.28)$ & $9(13.85)$ & \\
\hline 21-30 years & $107(51.94)$ & $77(54.61)$ & $30(46.15)$ & \\
\hline $31-40$ years & 41(19.9) & 27(19.15) & $14(46.15)$ & \\
\hline$\geq 40$ years & $19(9.22)$ & $7(4.96)$ & $12(18.46)$ & \\
\hline Education & & & & $<0.001$ \\
\hline None & $45(22.96)$ & $39(27.86)$ & $6(10.71)$ & \\
\hline Primary & $42(21.43)$ & $38(27.14))$ & $4(7.14)$ & \\
\hline Middle/JHS & $61(31.12)$ & $44(31.43)$ & $17(30.36)$ & \\
\hline Secondary/SHS+ & $48(24.49)$ & $19(12.86)$ & $29(31.29)$ & \\
\hline Marital Status & & & & 0.05 \\
\hline Married & $103(50.74)$ & $82(58.16)$ & 21(33.87) & \\
\hline Daily Income & & & & $<0.001$ \\
\hline$\leq$ GHS 20 & $36(18.00)$ & $26(18.44)$ & $10(16.95)$ & \\
\hline GHS 20-40 & $59(29.5)$ & $46(32.62)$ & $13(22.03)$ & \\
\hline GHS 41-60 & $57(28.5)$ & $38(26.95)$ & $19(32.2)$ & \\
\hline GHS 61+ & $48(24.0)$ & $31(20.91)$ & $16(3.28)$ & \\
\hline
\end{tabular}


Table 1. Cont.

\begin{tabular}{|c|c|c|c|c|}
\hline Variable & $\begin{array}{c}\text { Total } \\
(\mathrm{N}=207)\end{array}$ & $\begin{array}{c}\text { E-Waste Workers } \\
(\mathrm{N}=142)\end{array}$ & $\begin{array}{c}\text { Non E-Waste } \\
\text { Workers }(\mathrm{N}=65)\end{array}$ & $p$-Value \\
\hline & n (\%) & n (\%) & n (\%) & \\
\hline \multicolumn{5}{|l|}{ Living arrangements } \\
\hline Sleep location after work & & & & $<0.001$ \\
\hline On the site & $59(42.45)$ & $59(42.45)$ & - & \\
\hline Off site, but within $1 \mathrm{~km}$ of Agbogbloshie & $66(34.20)$ & $66(47.48)$ & - & \\
\hline More than $1 \mathrm{~km}$ away & & - & $65(100.0)$ & \\
\hline Indoor cooking & & & & $<0.001$ \\
\hline Yes & $45(22.73)$ & 22(15.94) & $23(38.33)$ & \\
\hline \multicolumn{5}{|l|}{ Lifestyle habits } \\
\hline Alcohol use & & & & 0.181 \\
\hline Current & 24(11.94) & 19(13.48) & $5(8.33)$ & \\
\hline Previous & $7(3.48)$ & $3(2.13)$ & $4(6.67)$ & \\
\hline Never & $170(84.58)$ & $119(84.40)$ & $51(85.00)$ & \\
\hline Cigarette smoking & & & & 0.001 \\
\hline Current & $50(25.13)$ & $45(32.65)$ & $6(10)$ & \\
\hline Never & $149(74.87)$ & $95(68.35)$ & $54(90)$ & \\
\hline \multicolumn{5}{|l|}{ Medical History } \\
\hline Pulmonary Tuberculosis & & & & 0.86 \\
\hline Yes & $2(1)$ & $2(1.42)$ & $0(0)$ & \\
\hline Asthma & & & & 0.010 \\
\hline Yes & $7(3.48)$ & $5(3.55)$ & 2(3.33) & \\
\hline
\end{tabular}

The frequency of cigarette smoking among the e-waste workers was 32.65\% (45) compared to $10 \%$ (6) among the non- e-waste workers. The association was statistically significant $(p<0.001)$. No significant differences were observed for daily income, alcohol use and previous history of pulmonary tuberculosis among the study participants. However, there was a higher prevalence of self- reported past history of bronchial asthma among the e-waste workers compared to the control group [3.55\% and $3.33 \% /(p<0.01)]$.

\subsection{Seasonal and Site-Specific Variations of Particulate Matter in the Breathing Zone of Participants}

Our results show that PM concentrations varied across the seasons with the highest concentrations recorded during the harmattan season. Generally, the median/IQR concentrations of PM among the e-waste workers at Agbogbloshie and the control population across the dry, rainy and harmattan seasons were consistently higher than the WHO air quality standards of $25 \mu \mathrm{g} / \mathrm{m}^{3}$ and $50 \mu \mathrm{g} / \mathrm{m}^{3}$ per 24-h mean. The observed median $\mathrm{PM}_{2.5}$ concentration levels at the e-waste and control sites were $69.86 \pm 36.33,61.18 \pm 37.92$ and $70.69 \pm 4825 \mu \mathrm{g} / \mathrm{m}^{3}$ during the dry, rainy and harmattan seasons. In comparison, the concentrations for the control population were $34.88 \pm 0.14 .72,34.13 \pm 7.22$ and $50.21 \pm 169.64$ across the three seasons respectively $(p<0.001, p<0.001$ and $p=0.950)$ [Table S1]. PM2.5 concentrations were $2-3 x$ times higher among the e-waste workers compared to the control group. The highest concentration of $\mathrm{PM}_{2.5}$ were recorded during the harmattan season with a significant association observed during the dry and rainy seasons $(p<0.001)$. The mean levels of $\mathrm{PM}_{2.5}$ among the e-waste workers were approximately twice that of the control population $(p<0.001)$. Similar trends were observed for the PM2.5-10 fraction across the dry, rainy and harmattan seasons $\left[94.26 \pm 87.34 \mu \mathrm{g} / \mathrm{m}^{3}\right.$ vs. $\left.68.23 \pm 63.31 \mu \mathrm{g} / \mathrm{m}^{3} ; p=0.009\right] ;\left[48.88 \pm 84.68 \mu \mathrm{g} / \mathrm{m}^{3}\right.$ vs. $\left.34.74 \pm 55.41 \mu \mathrm{g} / \mathrm{m}^{3} ; p=0.009\right]$ and $\left[54.30 \pm 126.38 \mu \mathrm{g} / \mathrm{m}^{3}\right.$ vs. $\left.31.59 \pm 383.81 \mu \mathrm{g} / \mathrm{m}^{3} ; p=0.960\right]$ respectively. Concentration of PM10 during the three seasons were $214.43 \pm 154.46 \mu \mathrm{g} / \mathrm{m}^{3}, 173.49 \pm 96.12 \mu \mathrm{g} / \mathrm{m}^{3}$ and $181.64 \pm 104.46 \mu \mathrm{g} / \mathrm{m}^{3}$ among the e-waste workers [118.12 $\pm 79.99 \mu \mathrm{g} / \mathrm{m}^{3} / p \leq 0.001,99.35 \pm 107.1 \mu \mathrm{g} / \mathrm{m}^{3} / p \leq 0.001$ and $395.57 \pm 412 / p=0.998]$ among the control participants.

Further analysis was conducted to determine the variation of PM in the breathing zone of the e-waste work- specific job categories across the sampling period and compared to the control population [Table S2]. Generally, the median/IQR concentration of PM $(2.5,2.5-10$ and $10 \mu \mathrm{m})$ in 
the breathing zone of the e-waste worker categories were consistently higher across the seasons and the associations were statistically significant. Moreover, we consistently observed the highest concentrations of PM $(2.5,2.5-10$ and $10 \mu \mathrm{m})$ among the e-waste burners across the seasons compared to the non-burners (dismantlers, sorters and collectors). High concentrations of PM (2.5, 2.5-10 and $10 \mu \mathrm{m}$ ) among collectors could be attributed to PM exposure from vehicular traffic as collectors trek around scavenging for wasted electrical gadgets for recycling.

\subsection{Measurement of Lung Function Parameters among Study Participants}

The mean $( \pm \mathrm{sd})$ of the lung function of participants across the waves have been captured in [Table S3]. Generally, lung function parameters were significantly lower among e-waste workers than controls. FEV1 and FVC ranged from $[2.83 \pm 0.54 \mathrm{~L} / \mathrm{s}, 3.84 \pm 1.02 \mathrm{~L}]$ and $[2.95 \pm 0.54 \mathrm{~L}, 3.85 \pm 1.23 \mathrm{~L}]$ respectively among e-waste workers and the control group across the three seasons. The mean FEV1and FVC for the control group was slightly higher than the e-waste workers, however, the association was not statistically significant. The FEV1/FVC ratio were however lower among the e-waste workers compared to the control group ( $p \leq 0.001, p=0.007$ and $p=0.007$ ) across the dry, rainy and harmattan seasons respectively. Comparing the lung function parameters (FEV1, FVC, PEF and FEV1/FVC) among the e-waste and the non-waste workers the boxplot [Figure S1]. Generally, within site, FVC and FEV1 did not significantly vary across the seasons. It was observed that there is a greater variability as well as larger outliers for Agbogbloshie compared to Madina. At $95 \%$ confidence interval, the true medians for FEV1 and FVC did not differ significantly across the sites. Conversely, PEF and FEV1/FVC showed greater variability for Madina- Zongo participants compared to Agbogbloshie. Though the true medians appears not to differ at both sites for PEF and FEV1/FVC, that of Madina was observed to be higher compared to participants at the Agbogbloshie site.

\subsection{Effect of Personal PM Exposure on Lung Function}

Results show that PM $(2.5,2.5-10$ and $10 \mu \mathrm{m})$ exposure affected the lung function parameters of the e-waste workers although the change in the effect sizes were small [Table S5]. The results of the study showed that PM $(2.5,2.5-10$ and $10 \mu \mathrm{m})$ in personal air was not significantly associated with lung function percentage of predicted at a $95 \%$ confidence level. The association was not statistically significant even after adjusting for potential confounders including seasons, job category, smoking status, past history of asthma, age, BMI and height [Table 2].

We further assessed the association between lung function parameters and the effects of the potential confounding factors [Table S4]. Seasonality significantly influenced all the lung function parameters. It was observed that during the rainy season, FEV1 decreased by $1.3 \%[\beta=-0.013 ; 95 \%$ CI: $-0.124-0.098$ ], FVC by $8.2 \%$ [ $\beta=-0.082 ; 95 \%$ CI: $-0.014-0.177]$, FEV1/FVC ratio decreased by $5.9 \%$ [ $\beta=-0.033 ; 95 \%$ CI: $-0.87-0.021]]$, PEF by $12.5 \%$ [ $\beta=-3.133 ; 95 \%$ CI: $-0.243,-0.022]$, and FEF25-75 by $17.9[\beta=-0.266 ; 95 \%$ CI: $-0.437,0.094]$. However, there were no significant differences at $5 \%$ level of significance. Greater decreases were also observed during the harmattan season, (FEV1 $-7.5 \%$ [ $\beta=-0.075 ; 95 \%$ CI: $-0.165-0.051]$, FVC $-2.4 \%$ [ $\beta=-0.024 ; 95 \%$ CI: $-0.102-0.052]$, FEV1/FVC ratio $-3.3 \%$ [ $\beta=-0.033 ; 95 \%$ CI: $-0.87-0.021]$, PEF $-13.3 \% \%$ [ $\beta=-3.133 ; 95 \%$ CI: $-0.243,-0.022]$ and FEF $25-75$ by $26.6 \%$ [ $\beta=-0.266$; $95 \%$ CI: $-0.437,0.094]$. Harmattan season showed significant influence especially on PEF and FEF 25-75.

With respect to job category, e-waste burners showed the highest decreases in their lung function parameters compared to the other job categories. The risk of work as a burner was predicted to decreased FEV1 by $4.5 \%$ [ $\beta=-0.045 ; 95 \%$ CI: $-0.151-0.061]$, FEV1/FVC by $6.0 \%$ [ $\beta=-0.060 ; 95 \%$ CI: $-0.123-0.004]$, PEF by $14.2 \%$ among e-waste burners [ $\beta=-0.142 ; 95 \% \mathrm{CI}:-0.278,-0.008$ ] and $\mathrm{FEF}_{25-75}$ by $22.5 \%$ [ $\beta=-0.225 ; 95 \% \mathrm{CI}:-0.451-0.001]$. Past history of Asthma was also significantly associated with the lung function parameters. Specifically, participants with a previous history of Asthma were predicted to have decreased FEV1 by $35.8 \%$ [ $\beta=-0.358$; 95\% CI: $-0.590,0.125$ ] [Table S4]. 
Table 2. Percent change (\%) and 95\%CI in lung function parameters per interquartile change range (IQR) of the respective PM (results from random effects linear regression models, $p \leq 0.05)$.

\begin{tabular}{|c|c|c|c|c|c|c|c|c|c|c|}
\hline & FEV1 & & FVC & & FEV1/FVC & & PEF & & FEF25-75 & \\
\hline PM Fraction & $\beta[95 \% \mathrm{CI}]$ & $p$-Value & $\beta[95 \% \mathrm{CI}]$ & $p$-Value & $\beta[95 \% \mathrm{CI}]$ & $p$-Value & $\beta[95 \% \mathrm{CI}]$ & $p$-Value & $\beta[95 \% \mathrm{CI}]$ & $p$-Value \\
\hline PM2.5 & $-0.001(-0.005,0.004)$ & 0.777 & $-0.001(-0.006,0.003)$ & 0.531 & $-0.001(-0.004,0.002)$ & 0.702 & $0.006(-0.001,0.012)$ & 0.098 & $0.005(-0.002,0.012)$ & 0.181 \\
\hline PM10 & $-0.001(-0.006,0.004)$ & 0.651 & $-0.002(-0.007,0.003)$ & 0.394 & $-0.001(-0.004,0.003)$ & 0.773 & $0.007(-0.002,0.017)$ & 0.121 & $0.012(0.003,0.021)$ & 0.013 \\
\hline PM2.5-10 & $0.002(-0.006,0.009)$ & 0.630 & $0.003(-0.004,0.010)$ & 0.390 & $0.001(-0.004,0.005)$ & 0.842 & $-0.008(-0.020,0.003)$ & 0.163 & $-0.015(-0.026,-0.003)$ & 0.010 \\
\hline
\end{tabular}

* Adjusted for Age, BMI, indoor cooking, seasonal variation, cigarette smoking, and job category Abbreviations: FEV1—Forced expiratory volume in one second; FVC—forced vital capacity; FEV1/FVC — ratio of Forced expiratory volume in one second and forced vital capacity; PEF—Peak vital capacity; FEF25-75-forced expiratory flow 25-75; FEV1/FVC ratio $\leq 0.7$. $\beta$-Coefficient, CI: confidence interval. Bolden p-values are statistically significant. 


\section{Discussion}

Our study examined the effects of PM (2.5, 2.5-10 and $10 \mu \mathrm{m})$ exposure in personal air on lung function among e-waste workers at Agbogbloshie, an informal recycling site and a control population from Madina-Zongo, in Accra Ghana. PM concentrations were consistently 2-3 times higher among the e-waste workers compared to the control group. The median/IQR values of PM (2.5, 2.5-10 and $10 \mu \mathrm{m})$ concentrations across the three seasons at both sites exceeded the WHO air quality standards of $25 \mu \mathrm{g} / \mathrm{m}^{3}$ and $50 \mu \mathrm{g} / \mathrm{m}^{3}$ per 24-hour mean and the average in-country ambient $\mathrm{PM}_{2.5}$ concentration levels of $35 \mu \mathrm{g} / \mathrm{m}$ [32]. [33], also reported significantly high concentrations of PM $(2.5,2.5-10$ and $10 \mu \mathrm{m})$ in the breathing zone of individuals who were involved in consistent burning of e-waste in Thailand. They reported mean PM2.5 and PM 2.5-10 concentrations of $441 \mu \mathrm{g} / \mathrm{m}^{3}$ and $2274 \mu \mathrm{g} / \mathrm{m}^{3}$ respectively.

Lung function measurement is an objective measure of respiratory health and a predictor of cardiopulmonary morbidity and mortality [6]. The larger airway parameters of lung function test such as FVC, FEV1, and FVC/FEV1 measure lung capacity and large airway resistance and have been commonly used in previous occupational studies to assess the relationship between particulate matter air pollution and pulmonary function [9,10,34-38]. Although the effect sizes for assessing the association of PM exposure on lung function parameters were small, it does not eliminate the potential adverse effects on lung function of the workers. In fact, according to world Health Organization (WHO, 2005) [39], there is no evidence of a safe threshold below which no adverse health effects of PM may occur. We postulate that competent immune status, age and the healthy worker effect may have contributed to the small and statistically insignificant effect observed in the e-waste workers. Consistent with our findings, previous studies conducted in occupational settings with high exposures to $\mathrm{PM}(2.5,2.5-10$ and $10 \mu \mathrm{m})$ [9,40-42] reported significant decline in lung function parameters (FEV1, FVC, FEV1/FVC), among the study participants due to exposures to PM2.5, PM 2.5-10 and PM10. Similarly, our study found a significant risk of lung function decline among e-waste workers, from exposure to high concentration of PM. To the best of our knowledge there has been no published studies examining the associated effects of PM exposure on lung function among e-waste workers. However, Amoabeng Nti, (2015) in a master's thesis, assessed the effect of heavy metals in blood on the lung function of 20 e-waste burners from Agbogbloshie and reported that $\mathrm{Pb}$ in blood reduced FVC by $0.20 \mathrm{~L}, \mathrm{Cd}$ in urine reduced FVC by $0.143 \mathrm{~L}$, Ni in urine reduced FVC by $0.294 \mathrm{~L}$ [43]. However, none of the associations between the heavy metals and FVC were significant. Also, two cross-sectional studies conducted at informal e-waste recycling sites in China and examined the association between exposure to heavy metals in particulates and lung function among children living near e-waste dumpsite in Guiyi $[44,45]$. We observed a consistent decline in FEV1 percentage of predicted among all the e-waste worker categories, more among burners than dismantlers, after adjusting for seasonal variation, age, and cigarette smoking. The effects of cigarette smoking, job category and indoor cooking, among e-waste workers were higher risk factors for reduced lung function. Our study showed a negative association of cigarette smoking on the lung function parameters. This is in contrast with findings from other occupational studies where workers were exposed to PM-related pollutants. Szram et al., (2012) conducted a systematic review and meta-analysis of welding fumes exposure on lung function among welders and reported $-9.0 \mathrm{~mL} /$ year $^{-1}(95 \% \mathrm{CI}-22.5-4.5 ; p=50.193)$ in FEV1 decline between welders and non-welders and an annual FEV1 decline between welders and controls with smoking history of $-13.7 \mathrm{~mL} /$ year $^{-1}$ (95\% CI -33.6-6.3; $\left.p=50.179\right)$ [44]. Bolund and colleagues 2015) also conducted a longitudinal study among young farmers and reported a negative effect of $[-0.12, p=0.006]$ and $[-0.15$, $p=0.009$ ] on FEV1, FEV1/FVC and FVC respectively [43] and that current smoking had a deleterious effect on lung function. Our study findings further corroborate previous studies that continuous exposure to PM2.5, PM 2.5-10 and PM10 may predispose to increased risk for lung function decline and chronic respiratory disease [2,9,12,19].

Lung function measurement is an objective measure of respiratory health and a predictor of cardiopulmonary morbidity and mortality [6]. The larger airway parameters of lung function test such as FVC, FEV1, and FVC/FEV1 measure lung capacity and large airway resistance and have 
been commonly used in previous occupational studies to assess the relationship between particulate matter air pollution and pulmonary function [9,10,34-38]. Although the effect sizes for assessing the association of PM exposure on lung function parameters were small, it does not eliminate the potential adverse effects on lung function of the workers. In fact, according to world Health Organization (WHO, 2005) [39], there is no evidence of a safe threshold below which no adverse health effects of PM may occur. We postulate that competent immune status, age and the healthy worker effect may have contributed to the small and statistically insignificant effect observed in the e-waste workers. Consistent with our findings, previous studies conducted in occupational settings with high exposures to $\mathrm{PM}(2.5,2.5-10$ and $10 \mu \mathrm{m})$ [9,40-42] reported significant decline in lung function parameters (FEV1, FVC, FEV1/FVC), among the study participants due to exposures to PM2.5, PM 2.5-10 and PM10. Similarly, our study found a significant risk of lung function decline among e-waste workers, from exposure to high concentration of PM. To the best of our knowledge there has been no published studies examining the associated effects of PM exposure on lung function among e-waste workers. However, Amoabeng Nti, (2015) in a master's thesis, assessed the effect of heavy metals in blood on the lung function of $20 \mathrm{e}$-waste burners from Agbogbloshie and reported that $\mathrm{Pb}$ in blood reduced $\mathrm{FVC}$ by $0.20 \mathrm{~L}, \mathrm{Cd}$ in urine reduced FVC by $0.143 \mathrm{~L}$, Ni in urine reduced FVC by $0.294 \mathrm{~L}$ [43]. However, none of the associations between the heavy metals and FVC were significant. Also, two cross-sectional studies conducted at informal e-waste recycling sites in China and examined the association between exposure to heavy metals in particulates and lung function among children living near e-waste dumpsite in Guiyi $[44,45]$. We observed a consistent decline in FEV1 percentage of predicted among all the e-waste worker categories, more among burners than dismantlers, after adjusting for seasonal variation, age, and cigarette smoking. The effects of cigarette smoking, job category and indoor cooking, among e-waste workers were higher risk factors for reduced lung function. Our study showed a negative association of cigarette smoking on the lung function parameters. This is in contrast with findings from other occupational studies where workers were exposed to PM-related pollutants. Szram et al., (2012) conducted a systematic review and meta-analysis of welding fumes exposure on lung function among welders and reported $-9.0 \mathrm{~mL} /$ year- $^{1}(95 \% \mathrm{CI}-22.5-4.5 ; p=50.193)$ in FEV1 decline between welders and non-welders and an annual FEV1 decline between welders and controls with smoking history of $-13.7 \mathrm{~mL} /$ year- (95\% CI $-33.6-6.3 ; p=50.179)$ [44]. Bolund and colleagues 2015) also conducted a longitudinal study among young farmers and reported a negative effect of $[-0.12, p=0.006]$ and $[-0.15$, $p=0.009$ ] on FEV1, FEV1/FVC and FVC respectively [43] and that current smoking had a deleterious effect on lung function. Our study findings further corroborate previous studies that continuous exposure to PM2.5, PM 2.5-10 and PM10 may predispose to increased risk for lung function decline and chronic respiratory disease $[2,9,12,19]$.

Furthermore, the higher increases in the reduction of smaller airway parameters (PEF and FEF25-75\%) suggest that the e-waste workers may be at an increased risk for small airway diseases such as occupational asthma, bronchitis, bronchiolitis and COPD due to airway obstruction. Small airways (bronchioles) appear particularly vulnerable to obstructive diseases because of their narrow lumen. Thus, many particulates may be deposited there making them more susceptible to complete obstruction than larger airways.

There are other potential sources of inhalational exposures that may affect the respiratory function of the informal e-waste workers. These include gaseous (e.g. nitrogen dioxide and ozone), organic (e.g., PAHs) and inorganic (heavy metals and vehicular exhaust emissions), other pollutants from e-waste recycling activities, refuse burning at nearby landfill site and combustion emissions from various informal local restaurants (chop bars) dotted around the recycling site. However, due to financial constraints, their effects were not evaluated in this study.

Our study had some important strengths. To the best of our knowledge, this is the first longitudinal cohort study with repeated measures to investigate the association between recurrent exposure to PM2.5, PM 2.5-10 and PM10 in the breathing zone and lung function parameters of informal e-waste workers. 
Important limitations to our study must be noted. Firstly, the observed effects may be biased by the assumption of the exposure time and lung function measurement. The 4-h mean PM concentration on the days of spirometry measurements, was assumed to be suitable for this study. Secondly, we realize that the best estimates require the use of monitoring devices that can be carried by e-waste workers over a longer period than four working hours. Thirdly, the evaluation of the effects of air pollutants by season would further have been strengthened if the interaction between gaseous pollutants such as ozone, nitrogen dioxide and UFP PM were considered.

Fourthly, other particulates can also occur in both gaseous and liquid states, however, the concentrations of PM were evaluated only by mass concentration. There is the need for further evaluation to include the various states of matter. Finally, indoor air pollution should be considered and objectively determined in future studies. Indoor biomass fuel use was considered as a confounding factor, however, an objective measurement for direct effect assessment would have been ideal. Further research is needed to examine the effects of PM pollution on e-waste workers' lung function and PM concentrations exposure.

\section{Conclusions}

Exposure to elevated levels of PM in the breathing zone is a risk factor for decreased lung function parameters among healthy e-waste workers resulting in reduced spirometry results. The negative effects of $\operatorname{PM}(2.5,2.5-10$ and $10 \mu \mathrm{m})$ on the lung function of healthy e-waste workers requires an effective workplace ambient air quality management program, necessary to reduce the workers' respiratory health risks. There is the need for improvement in the work layout, methods and procedures with reduced exposure to hazardous agents injurious to the lungs of e-waste workers. Health and safety promotion campaigns should be conducted emphasizing the hazards of exposure to fine and coarse PM to mitigate these health effects. This study however, was limited by shorter duration of personal PM measurement as well as shorter intervals for subsequent follow-up sampling periods. A longer duration of sampling would have further strengthened the assessment of changes in lung function from PM exposures. Being a biological phenomenon, the bodies coping mechanisms and healthy worker effects may delay any observable clinical adverse effects.

Supplementary Materials: The following are available online at http:/www.mdpi.com/1660-4601/17/9/3042/s1, Figure S1: Descriptive statistics of lung function parameters among study participants across study period, Table S1. Concentrations of PM in the breathing zone of e-waste workers and controls across seasons; Table S2. Seasonal Variation of particulate matter in the breathing zone of e-waste worker job categories and controls over time; Table S3. Seasonal variation of lung function parameters among study participants across the study sites; Table S4. Associated effects of covariates on the lung function parameters among e-waste workers and control population; Table S5. Percent change (\%) and $95 \% \mathrm{CI}$ in lung function parameters per interquartile change range (IQR) of the respective PM (crude results from random effects linear regression models, $p<0.05$ ).

Author Contributions: Conceptualization, A.A.A.N., T.G.R., J.N.F. and J.A.-M.; Methodology, A.A.A.N., T.G.R., J.N.F. and J.A.M.; Software, T.G.R.; Investigation, A.A.A.N., T.G.R., J.N.F., J.A.-M., A.A.A., S.A.T. and L.K.; Validation and formal analysis, A.A.A.N., P.K.B. and D.D.; Resources, T.G.R. and J.N.F.; Data curation, A.A.A.N., P.K.B., L.K. and D.D.; Writing-original draft preparation, A.A.A.N.; Writing-review and editing, A.A.A.N., T.G.R., J.N.F., J.A.-M., S.B., N.B., A.A.A., P.K.B., P.T., S.A.T. and L.K.; Visualization, A.A.A.N. and D.D.; Supervision, T.G.R., J.N.F., J.A.-M., A.A.A., P.K.B., P.T. and S.B.; Project administration, T.G.R., J.N.F.; Funding acquisition, T.G.R. and J.N.F. All authors have read and agreed to the published version of the manuscript.

Funding: This research was funded by the West Africa-Michigan CHARTER in GEOHealth with funding from the United States National Institutes of Health/Fogarty International Center (US NIH/FIC) (paired grant no 1U2RTW010110-01/5U01TW010101).

Acknowledgments: Messers Emmanuel Baiden, Kofi Adjabeng and Bright Frimpong are kindly acknowledged for their logistic and statistical support.

Conflicts of Interest: The authors declare no conflict of interest. The funders had no role in the design of the study; in the collection, analyses, or interpretation of data; in the writing of the manuscript, or in the decision to publish the results. 


\section{References}

1. Driscoll, T.; Nelson, D.I.; Steenland, K.; Leigh, J.; Fingerhut, M.; Prüss-Üstün, A.; Concha-Barrientos, M. The global burden of non-malignant respiratory disease due to occupational airborne exposures. Am. J. Ind. Med. 2005, 48, 432-445. [CrossRef]

2. Landrigan, P.J.; Fuller, R.; Acosta, N.J.R.; Adeyi, O.; Arnold, R.; Basu, N.N.; Steiner, A. The Lancet Commission on pollution and health. Lancet 2018, 391, 462-512. [CrossRef]

3. Brook, R.D.; Rajagopalan, S.; Pope, C.A.; Brook, J.R.; Bhatnagar, A.; Diez-Roux, A.V.; Holguin, F.; Hong, Y.; Luepker, R.V.; Mittleman, M.A.; et al. Particulate Matter Air Pollution and Cardiovascular Disease. Circulation 2010, 121, 2331-2378. [CrossRef] [PubMed]

4. Valavanidis, A.; Thomais, V.; Konstantinos, F. Air Pollution as a Significant Cause of Diseases and Premature Death. Ambient Air Pollution in Urban Areas and Indoor Air Pollution are Associated with Adverse Health Effects and Premature Mortality. 2016. Available online: https://www.researchgate.net/publication/309557770 (accessed on 24 April 2020).

5. Anderson, J.O.; Thundiyil, J.G.; Stolbach, A. Clearing the Air: A Review of the Effects of Particulate Matter Air Pollution on Human Health. J. Med. Toxicol. 2012, 8, 166-175. [CrossRef]

6. Paulin, L.M.; Hansel, N. Particulate air pollution and impaired lung function. F1000Research 2016, 5, 201. [CrossRef] [PubMed]

7. Panis, L.I.; Provost, E.B.; Cox, B.; Louwies, T.; Laeremans, M.; Standaert, A.; Dons, E.; Holmstock, L.; Nawrot, T.S.; De Boever, P. Short-term air pollution exposure decreases lung function: A repeated measures study in healthy adults. Environ. Health 2017, 16, 60. [CrossRef]

8. Zeng, X.; Xu, X.; Boezen, H.M.; Vonk, J.M.; Wu, W.; Huo, X. Decreased lung function with mediation of blood parameters linked to e-waste lead and cadmium exposure in preschool children. Environ. Pollut. 2017, 230, 838-848. [CrossRef]

9. Girma, F.; Kebede, Z. Dust Exposure Associations with Lung Function among Ethiopian Steel Workers. Ann. Glob. Health 2019, 85, 85. [CrossRef] [PubMed]

10. Andersson, E.; Sällsten, G.; Lohman, S.; Neitzel, R.; Torén, K. Lung function and paper dust exposure among workers in a soft tissue paper mill. Int. Arch. Occup. Environ. Health 2019, 93, 105-110. [CrossRef] [PubMed]

11. Cohen, A.; Brauer, M.; Burnett, R.; Anderson, H.R.; Frostad, J.; Estep, K.; Balakrishnan, K.; Brunekreef, B.; Dandona, L.; Dandona, R.; et al. Estimates and 25-year trends of the global burden of disease attributable to ambient air pollution: An analysis of data from the Global Burden of Diseases Study 2015. Lancet 2017, 389, 1907-1918. [CrossRef]

12. Li, T.; Hu, R.; Chen, Z.; Li, Q.-Y.; Huang, S.-X.; Zhu, Z.; Zhou, L.-F. Fine particulate matter (PM2.5): The culprit for chronic lung diseases in China. Chronic Dis. Transl. Med. 2018, 4, 176-186. [CrossRef] [PubMed]

13. Akormedi, M.; Asampong, E.; Fobil, J.N. Working conditions and environmental exposures among electronic waste workers in Ghana. Int. J. Occup. Environ. Health 2013, 19, 278-286. [CrossRef] [PubMed]

14. Amankwaa, E.F.; Tsikudo, K.A.A.; Bowman, J.A.; Bowman, J. 'Away' is a place: The impact of electronic waste recycling on blood lead levels in Ghana. Sci. Total. Environ. 2017, 601, 1566-1574. [CrossRef] [PubMed]

15. Caravanos, J.; Clarke, E.E.; Osei, C.S.; Amoyaw-Osei, Y. Exploratory Health Assessment of Chemical Exposures at E-Waste Recycling and Scrapyard Facility in Ghana. J. Health Pollut. 2013, 3, 11-22. [CrossRef]

16. Caravanos, J.; Clark, E.; Fuller, R.; Lambertson, C. Assessing Worker and Environmental Chemical Exposure Risks at an e-Waste Recycling and Disposal Site in Accra, Ghana. J. Health Pollut. 2011, 1, 16-25. [CrossRef]

17. Gawande, U.; Khanvilkar, A.; Kadam, S.; Salvitthal, G. Effects of ambient air pollution on respiratory health of adults: Findings from a cross-sectional study in Chandrapur, Maharashtra, India. Int. J. Res. Med. Sci. 2016, 4, 1546-1557. [CrossRef]

18. Chow, J.C.; Watson, J.; Mauderly, J.L.; Costa, D.L.; Wyzga, R.E.; Vedal, S.; Hidy, G.M.; Altshuler, S.L.; Marrack, D.; Heuss, J.M.; et al. Health effects of fine particulate air pollution: Lines that connect. J. Air Waste Manag. Assoc. 2006, 56, 1368-1380. [CrossRef]

19. Pope, C.A.; Dockery, D.W. Health effects of fine particulate air pollution: Lines that connect. J. Air Waste Manag. Assoc. 2006, 56, 709-742. [CrossRef]

20. Cortez-Lugo, M.; Ramírez-Aguilar, M.; Perez-Padilla, R.; Sansores, R.; Ramírez-Venegas, A.; Barraza-Villarreal, A. Effect of Personal Exposure to PM2.5 on Respiratory Health in a Mexican Panel of Patients with COPD. Int. J. Environ. Res. Public Health 2015, 12, 10635-10647. [CrossRef] 
21. Sharma, D.C. Emissions from e-waste recycling threaten workers' health. Lancet Respir. Med. 2015, 3, 847-848. [CrossRef]

22. Ghana e-Waste Country Assessment. Available online: http://www.basel.int/Portals/4/BaselConvention/ docs/eWaste/E-wasteAssessmentGhana.pdf (accessed on 15 January 2011).

23. The World's Worst 2013: The Top Ten Toxic Threats Cleanup, Progress, and Oongoing Challenges. Available online: https://www.worstpolluted.org/docs/TopTenThreats2013.pdf (accessed on 15 January 2020).

24. Heacock, M.L.; Kelly, C.B.; Asante, K.A.; Birnbaum, L.S.; Bergman, A.L.; Brune, M.-N.; Buka, I.; Carpenter, D.O.; Chen, A.; Huo, X.; et al. E-Waste and Harm to Vulnerable Populations: A Growing Global Problem. Environ. Health Perspect. 2015, 124, 550-555. [CrossRef]

25. Oberhauser, A.M.; Hanson, K.T. Negotiating Livelihoods and Scale in the Context of Neoliberal Globalization: Perspectives from Accra, Ghana. Afr. Geogr. Rev. 2007, 26, 11-36. [CrossRef]

26. Sunnu, A.K.; Afeti, G.; Resch, F. Daily Levels of the Harmattan Dust near the Gulf of Guinea over 15 Years: 1996-2011. Environ. Ecol. Res. 2018, 6, 593-604. [CrossRef]

27. Laskaris, Z.; Milando, C.; Batterman, S.; Mukherjee, B.; Basu, N.; O’Neill, M.S.; Robins, T.G.; Fobil, J.N. Derivation of Time-Activity Data Using Wearable Cameras and Measures of Personal Inhalation Exposure among Workers at an Informal Electronic-Waste Recovery Site in Ghana. Ann. Work. Expo. Health 2019, 63, 829-841. [CrossRef] [PubMed]

28. Miller, M.; Hankinson, J.; Brusasco, V.; Burgos, F.; Casaburi, R.; Coates, A.; Crapo, R.; Enright, P.; Van Der Grinten, C.P.M.; Gustafsson, P.; et al. Standardisation of spirometry. Eur. Respir. J. 2005, 26, 319-338. [CrossRef]

29. Pellegrino, R.; Viegi, G.; Brusasco, V.; O Crapo, R.; Burgos, F.; Casaburi, R.; Coates, A.; Van Der Grinten, C.P.M.; Gustafsson, P.; Hankinson, J.; et al. Interpretative strategies for lung function tests. Eur. Respir. J. 2005, 26, 948-968. [CrossRef]

30. Hankinson, J.L.; Odencrantz, J.R.; Fedan, K.B. Spirometric Reference Values from a Sample of the General U.S. Population. Am. J. Respir. Crit. Care Med. 1999, 159, 179-187. [CrossRef]

31. Goldstein, H.; Diggle, P.J.; Liang, K.-Y.; Zeger, S.L. Analysis of Longitudinal Data. J. R. Stat. Soc. Ser. A Stat. Soc. 1995, 158, 345. [CrossRef]

32. Findings from the Global Burden of Disease Study 2017. Available online: http://www.healthdata.org/sites/ default/files/files/policy_report/2019/GBD_2017_Booklet.pdf (accessed on 15 January 2020).

33. Bungadaeng, S.; Prueksasit, T.; Siriwong, W. Inhalation exposure to respirable particulate matter among workers in relation to their e-waste open burning activities in Buriram Province, Thailand. Sustain. Environ. Res. 2019, 29, 1-12. [CrossRef]

34. Abaya, S.W.; Bråtveit, M.; Deressa, W.; Kumie, A.; Moen, B.E. Reduced Lung Function among Workers in Primary Coffee Processing Factories in Ethiopia: A Cross Sectional Study. Int. J. Environ. Res. Public Health 2018, 15, 2415. [CrossRef]

35. Demeke, D.; Haile, D.W. Assessment of Respiratory Symptoms and Pulmonary Function Status among Workers of Flour Mills in Addis Ababa, Ethiopia: Comparative Cross-Sectional Study. Pulm. Med. 2018, 2018, 1-7. [CrossRef] [PubMed]

36. Fareed, M.; Mahmoud, M.A.; Al-Dubai, S.A.R.; Khoja, A.T. Adverse Respiratory Health and Decline in Lung Functions among Workers of Riyadh Metro Railway Tunnel. Int. J. Med. Res. Health Sci. 2018, 7, 127-131.

37. Kumar, M.K.; George, L.S. Pulmonary function of automobile repair workers in the informal sector of Raichur urban. Int. J. Community Med. Public Health 2017, 4, 1510. [CrossRef]

38. Wong, T.-W.; Wong, A.H.S.; Lee, F.S.C.; Qiu, H. Respiratory health and lung function in Chinese restaurant kitchen workers. Occup. Environ. Med. 2011, 68, 746-752. [CrossRef]

39. Lodge, J.P., Jr. Air quality guidelines for Europe. Atmos. Environ. (1967) 1988, 22, 2070-2071. [CrossRef]

40. Szram, J.; Schofield, S.J.; Cosgrove, M.P.; Cullinan, P. Welding, longitudinal lung function decline and chronic respiratory symptoms: A systematic review of cohort studies. Eur. Respir. J. 2012, 42, 1186-1193. [CrossRef]

41. Haluza, D.; Moshammer, H.; Hochgatterer, K. Dust is in the Air. Part II: Effects of Occupational Exposure to Welding Fumes on Lung Function in a 9-Year Study. Lung 2013, 192, 111-117. [CrossRef]

42. Bolund, A.C.S.; Miller, M.; Basinas, I.; Elholm, G.; Omland, Ø.; Sigsgaard, T.; Schlünssen, V. The effect of occupational farming on lung function development in young adults: A 15-year follow-up study. Occup. Environ. Med. 2015, 72, 707-713. [CrossRef] 
43. Nti, A.A.A. Effects of E-Waste on Respiratory Function Among E-Waste Workers Engaged in Burning At Agbogbloshie, Accra. Master's Thesis, University of Ghana, Legon, Ghana, July 2015.

44. Zeng, X.; Xu, X.; Zheng, X.; Reponen, T.; Chen, A.; Huo, X. Heavy metals in PM 2.5 and in blood, and children's respiratory symptoms and asthma from an e-waste recycling area. Environ. Pollut. 2016, 210, 346-353. [CrossRef]

45. Zheng, G.; Xu, X.; Li, B.; Wu, K.; A Yekeen, T.; Huo, X. Association between lung function in school children and exposure to three transition metals from an e-waste recycling area. J. Expo. Sci. Environ. Epidemiol. 2012, 23, 67-72. [CrossRef]

(C) 2020 by the authors. Licensee MDPI, Basel, Switzerland. This article is an open access article distributed under the terms and conditions of the Creative Commons Attribution (CC BY) license (http://creativecommons.org/licenses/by/4.0/). 